\title{
Visibility and Ethical Considerations of Pakistani Universities Researchers on Google Scholar
}

\author{
Muhammad Asghar Khan ${ }^{1}$, Tariq Rahim Soomro ${ }^{2}$ \\ College of Computer Science and Information Systems Institute of Business Management \\ Karachi, Pakistan
}

\begin{abstract}
Maximizing visibility by using academic profiling sites is very crucial in the academic world to improve the readership of research papers published and constant evaluation of research quality. In this article, the authors focused on the visibility of Pakistani University scholars on Google Scholar (GS). An intelligent Web Bot (MAKGBOT) was developed to collect the scholarly data of all Pakistani scholars, whose data is publicly available on Google Scholar. The findings of this research show that $87 \%$ of Pakistani universities have a presence on Google Scholar. It analyzes the research performance of scholars based on the last five years' data from 2016 to 2020. Furthermore, the analysis reports the level of scholarly activities of all provinces and autonomous areas of Pakistan. This paper concludes by discussing the ethical issue of misrepresentation of information on the public profile and its consequences on the rankings of legitimate scholars.
\end{abstract}

Keywords-Google scholar; research visibility; Pakistani researchers; ethical considerations; web bot; research in Pakistan

\section{INTRODUCTION}

The establishment of a research University is an expensive task compared to a typical educational institute. Research Universities are expensive because they need to attract good researchers and provide state-of-the-art infrastructure for teaching and research environment. In developed countries, governments and organizations are investing an enormous amount of resources in research and development. Multinational companies sponsor research-funded projects at Universities to get the solution to the real-life problem they are facing at a lower cost compared to the establishment of their research and development team. However, in developing countries, the establishment of a research University is even a more difficult task due to the scarcity of resources. Pakistan as a third-world country is also facing a shortage of research Universities. Regulatory bodies, such as, the Higher Education Commission (HEC) of Pakistan is working hard to improve the research culture in existing Universities of Pakistan.

Researchers produce research papers to highlight their contribution to the domain of their specialization. In the last few years, there is a great motivation to measure the quality of research of individuals based on different indicators [1]. Two most common indicators are the number of the paper published by an author and the number of citations [2]. There is an interesting discussion within bibliometrics that either researcher focuses on productivity or on the impact of the paper? [3] [4]. One of the major challenges for a researcher is to secure funding for a research project. Different higher education funding bodies provide sponsorship based on publication count (such as the Australian Funding System [3], whereas others focused on the quality of paper e.g. Netherlands national research assessment [4].

The scarcity of resources for research projects is a common issue, especially in developing economies. Funding organizations, such as, governments and R\&D wings of multinational companies require to select competent researchers for their projects. The selection criteria are normally based on innovative idea and their impact on society after the completion of projects, however, the researcher's academic rankings and historical history of completion of projects were also considered when multiple competitors have the same level of creativity in their proposed projects. Different Indexing and abstracting services, such as, Scopus, Clarivative Analytics (Web of Science), and Google Scholar (GS) maintain the ranking of researches through different performance indicators, such as, the number of articles published, total citations, h-index, i10-index, Impact factor, etc. Google Scholar is a free and popular tool that helps to find scholars and their published articles along with performance indicators. Most University scholars create their Google Scholar profile to make their work visible over the Internet. In general, tight integration between Google Scholar and search engine improves the appearance of relevant search results from existing articles and helps to improve the number of a citation for authors of those papers.

This project extracts the important research matrices (for example, number of citations, the paper published, H-index, etc.) for all Pakistani university scholars whose profile is publicly available on GS. The authors of this study rank the universities based on their presence on GS and highlight the region of Pakistan where universities are more researchoriented. One of the contributions of this study is to list down the top researches of Pakistan and their academic affiliations. Furthermore, this study discusses the ethical issue of misrepresentation of information on academic profiles and its consequences on the ranking of legitimate scholars. The following sections provide a brief literature review, research methodology, limitation of the study, results \& findings, ethical consideration, and finally discussion and future work.

\section{LITERATURE REVIEW}

Most of the scientific work nowadays is published in the form of research papers in journals or conferences, which can be easily found in bibliographic databases [5]. PubMed, ScienceDirect, Scopus, Web of Science, and Google Scholar are among the most famous bibliographic databases used to 
find authors' profiles and relevant articles of interest by researchers. GS is a freely available academic search engine [6] that indexes scientific literature from a wide range of disciplines, record types, and languages, providing an outstanding set of additional offerings at the same time. The fact that it shows the number of citations obtained by each paper, irrespective of their origin, opened the door to a new type of bibliometric study, revolutionizing the comparison between academic performance, especially in the Humanities and Social Sciences [7]. Today, the majority of students and scholars are beginning to scan educational information in GS [8] [9]. Therefore, publications that are absent from the consequences pages of Google Scholar may also result in large readership losses and maybe even a decline in citations [10]. Anne-Wil Harzing in [11] claimed that GS can be used as a tool for citation analysis and described the benefits of GS over the ISI Web of Science along with the advantages and disadvantages of each tool.

Digital profiles are increasingly being used to assess potential writers, reviewers, and journal editors to exchange and collaborate on scholarly articles, and set up academic networks. Subsequently, simultaneous searches through the bibliographic databases and Websites, such as MEDLINE, Scopus, the Web of Science, and Google Scholar, make it possible to retrieve relevant items and navigate their extensive comparison through the author's profiles [12]. Editors of journals also refer to the profiles of their contributors in their editorial management systems, connected to bibliographic databases and search engines, in order to improve their quality and encourage the best contributors [13]. Furthermore, editors are strongly inspired to evaluate their contributors' academic profiles and Researcher IDs to avoid commenting on 'false' reviewers and misconduct of various types [14]. Alastair Smith [15] studied New Zealand's Performance-Based Research Funding (PBRF) evaluation system for universities and determined a very high correlation between PBRF output and the total number of citations return by GS. To improve the chance to secure more funding or to publish a paper in a reputed journal, few authors include fake papers in their profiles to increase the h-index and other research indicates or not verifying auto-generated papers suggested by Google Scholar, which results in more citations and number of publications. Such behavior raises many questions of ethical values, norms of societies, and financial pressures on researchers.

\section{METHODOLOGY}

A list of Pakistani Universities was retrieved from HEC [16]. HEC is the official body whose main responsibility is to regulate, fund, and accredited Universities and Degree Awarding Institutes (DAI) in Pakistan. There were 217 Universities/degree awarding institutes found in HEC accredited Universities database. HEC divided Pakistan into 4 provinces (Punjab, Sindh, Khyber Pakhtunkhwa, and Balochistan) and three autonomous areas (Gilgit Baltistan, Azad Jammu \& Kashmir, and Islamabad Capital Territory).

The main aim of this study is to collect the data from Google Scholar profiles for all Pakistani University researchers, whose data is publicly available. The collection of scholarly data for the whole country is a difficult task if performed manually. Therefore, there is a need to automate this data collection process. Authors of the paper have developed a Web Bot called "MAKGBOT", which crawls all University scholars profile automatically and collect the following attributes from the publicly available profiles of the researchers on Google Scholar:

1) Google Scholar ID.

2) Google Scholar Name.

3) Total Citations.

4) Affiliation.

5) h-index.

6) i10-index.

7) Citations in the year 2016.

8) Citations in the year 2017.

9) Citations in the year 2018.

10)Citations in the year 2019.

11)Citations in the year 2020.

12)Citations in the last five year.

13)Total papers published by Scholar (complete).

MAKGBOT is a Python script, which uses the beautifulsoup [17] library to scrape information from the Google Scholar Website. Beautifulsoup is a very useful tool for searching, iterating, and modifying parse trees. MAKGBOT is similar to Scholarly [18], but it differs in a way that MAKGBOT can retrieve information for a University rather than a single author. Universities list along with URL can be fed to MAKGBOT as a comma-separated values (CSV) file instead of passing one University name at a time. Furthermore, MAKGBOT provides extra information, such as, total papers published by scholars who were not present in Scholarly.

\section{LIMITATIONS OF THE STUDY}

The authors of this paper are aware that many Pakistani researchers have not created an account on Google Scholar or they have not set their profiles public. In this scenario, authors are unable to collect information about such researchers as the study focused was on the scholars whose profiles are publically available and visible. Furthermore, the authors noticed that a few authors have not changed their affiliation after switching their job to another institute. Therefore, the research contribution of such scholars will be counted towards their affiliation institute, which is verified, rather than where they are working currently. Furthermore, the authors are aware that the total number of papers and citations by a particular scholar may not be correct, as several authors set their profiles on the auto-generate mechanism and not annually verified the statistics and papers suggested by GS against their names.

Searching and collecting information for all researchers of a country is a time-consuming task. MAKGBOT restricted itself to limit the number of papers published by any author to 3000. As soon as a counter for the number of papers published by a single author reached 3000 , MAKGBOT moved to the next scholar of that University on the list. Paper publication and the addition of new scholars on Google Scholar is a continuous process. Therefore, it is entirely possible that authors may miss a few scholars and papers, which were added 
after 10 January 2021. There is a need for a system, which is capable to deals with continual queries and updates the existing records as soon as there are changes that exist on Google Scholar. Adding this capability in MAKGBOT is considered as future work.

\section{RESULTS AND FINDINGS}

Based on the data selected by MAKGBOT until 10 January 2021, the following results are observed:

The pie chart in Fig. 1 shows the percentage share of scholars by provinces of Pakistan. Punjab is the largest province with the highest population and the maximum number of recognized Universities. Therefore, it is clear that the majority $(33 \%)$ of the participants are from the Punjab region followed by Sindh (26\%), Khyber Pakhtunkhwa (21\%), Islamabad (12\%), Balochistan (4\%), Azad Jammu \& Kashmir (3\%) and Gilgit Baltistan (1\%). Results from MAKGBOT illustrate that the visibility of researchers on Google Scholar is proportional to the population of those areas. The only exception is Islamabad capital territory, where the numbers of scholars on GS are relatively higher if compared to other autonomous areas of Pakistan. This variation is might due to the fact that Pakistan's best universities are located in Islamabad (HEC ranking [19], QS Ranking [20], Times University ranking [21]). Furthermore, Universities from the capital region have the highest Google Scholar visibility rate $(100 \%)$ along with Gilgit Baltistan (100\%), where only two Universities are situated.

Fig. 2 displays the top ten Pakistani Universities on Google Scholar based on the total number of scholars available and/or visible. Universities with the highest representation on Google Scholar are located either in Islamabad or Punjab. National University of Sciences and Technology ranked top with 764 active participants followed by the University of Lahore, University of Management \& Technology, and Quaid e Azam University.

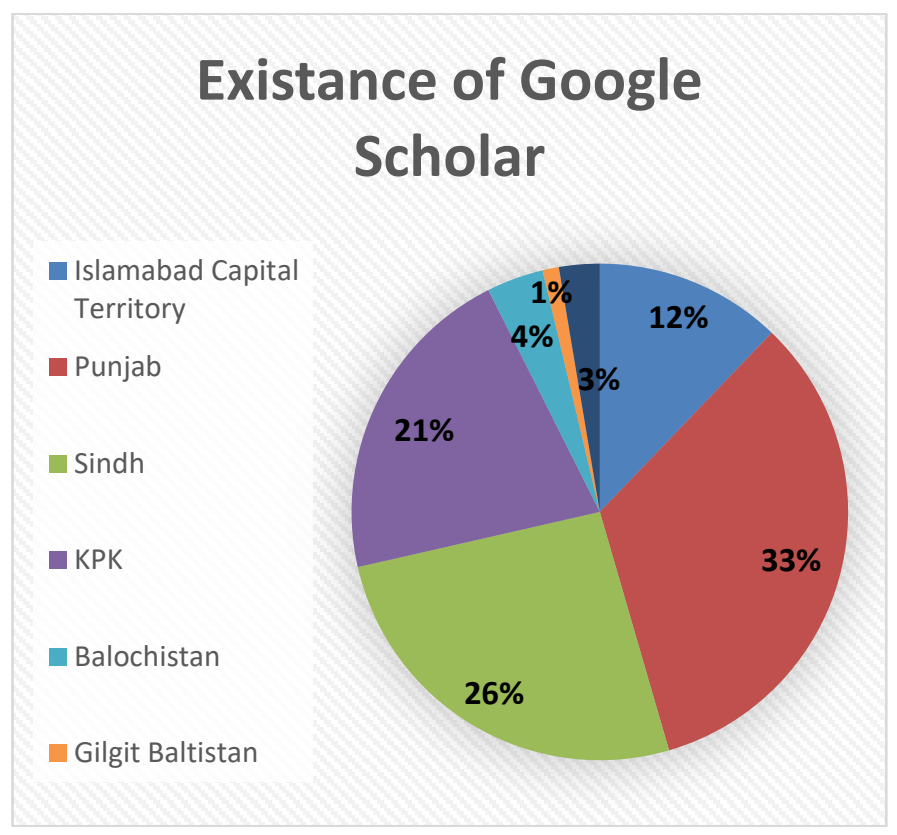

Fig. 1. The Percentage Share of Scholars by Provinces of Pakistan.

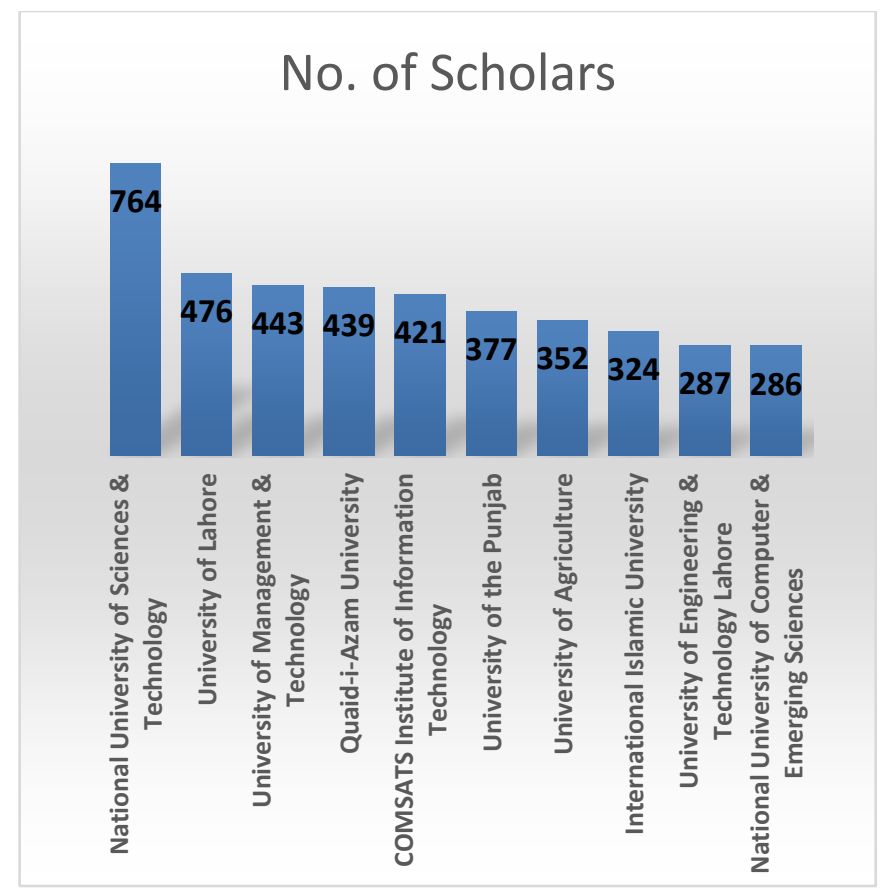

Fig. 2. Top Ten Pakistani Universities on Google Scholar by Number of Scholars.

The top three Universities in Punjab province by scholars count are the University of Lahore, University of Management and Technology, and the University of Punjab. The University of Lahore and the University of Management and Technology belong to the private sector. The University of Punjab is the oldest active University in Pakistan [22]. The top three Universities in Punjab are located in the provincial capital Lahore. There is a total of ten universities in the province of Punjab, which are not visible on GS. Table I shows the list of all Universities in Punjab province sorted by the total number of scholars visible.

The trend in Sindh province is slightly different as two out of three top positions are secured by public sector Universities. Aga Khan University ranked first, followed by Mehran University of Engineering and Technology and Univerity of Sindh, with scholar count 272, 255, and 244 respectively. Twelve Universities have no scholar whose profile is publically visible on Google Scholar. Table II illustrates the details of all Universities in the province of Sindh.

The visibility of scholars of Khyber Pakhtunkhwa Universities has resemblance with Sindh province as the top three positions were secured by public Universities. The number of scholar count difference between Abdul Wali Khan University and University of Engineering and Technology is only 23. Only one University of Khyber Pakhtunkhwa province is not visible at GS. Table III demonstrates the nittygritty rundown of all Universities in the region of Khyber Pakhtunkhwa.

Balochistan is the least populated province of Pakistan and only ten Universities are located in this region. A total of the three universities of Balochistan province are not visible on GS. Table IV highlights the important Google Scholar indicators. 
TABLE I. LIST OF ALL OF THE UNIVERSITIES OF PUNJAB ProvinCE

\begin{tabular}{|c|c|c|c|c|c|}
\hline University Name & $\begin{array}{l}\text { Total Number of } \\
\text { Scholars Visible }\end{array}$ & $\begin{array}{l}\text { Max of h- } \\
\text { index }\end{array}$ & $\begin{array}{l}\text { Max of } \\
\text { i10-index }\end{array}$ & $\begin{array}{l}\text { Sum of total } \\
\text { Citation }\end{array}$ & $\begin{array}{l}\text { Sum of Total } \\
\text { Paper Published }\end{array}$ \\
\hline University of Lahore & 476 & 92 & 354 & 123322 & 10322 \\
\hline University of Management \& Technology & 443 & 76 & 691 & 145506 & 17461 \\
\hline University of the Punjab & 377 & 76 & 689 & 249661 & 23499 \\
\hline University of Agriculture & 352 & 59 & 351 & 282540 & 23808 \\
\hline University of Engineering \& Technology Lahore & 287 & 81 & 780 & 141087 & 12379 \\
\hline Lahore University of Management Sciences & 272 & 66 & 649 & 117894 & 9556 \\
\hline Government College for Women University & 261 & 65 & 267 & 186651 & 15075 \\
\hline University of Sargodha & 244 & 73 & 723 & 124734 & 12245 \\
\hline Bahauddin Zakariya University & 239 & 71 & 638 & 213984 & 20075 \\
\hline University of Engineering \& Technology Taxila & 208 & 20 & 37 & 34790 & 4209 \\
\hline Islamia University & 208 & 64 & 546 & 153240 & 14664 \\
\hline University of Gujrat & 183 & 60 & 362 & 94814 & 9218 \\
\hline University of Veterinary \& Animal Sciences & 161 & 70 & 766 & 126843 & 14963 \\
\hline University of Central Punjab & 160 & 39 & 123 & 28374 & 3851 \\
\hline Pir Mehr Ali Shah Arid Agriculture University & 139 & 64 & 432 & 117638 & 9699 \\
\hline Government College University Lahore & 127 & 45 & 138 & 62838 & 5533 \\
\hline University of Education & 127 & 109 & 416 & 65497 & 4474 \\
\hline Lahore Garrison University & 104 & 48 & 374 & 20068 & 3251 \\
\hline Information Technology University of the Punjab & 95 & 33 & 75 & 17183 & 1519 \\
\hline Khawaja Freed University of Engineering \& Information Technology & 91 & 32 & 108 & 14860 & 2013 \\
\hline Lahore College for Women University & 81 & 18 & 23 & 11384 & 1717 \\
\hline Forman Christian College & 72 & 126 & 298 & 57448 & 2150 \\
\hline The Superior College & 72 & 51 & 218 & 29610 & 2986 \\
\hline National Textile University & 71 & 85 & 934 & 59762 & 7632 \\
\hline Muhammad Nawaz Shareef University of Agriculture & 62 & 27 & 70 & 19868 & 3948 \\
\hline National University of Medical Sciences & 52 & 51 & 477 & 39097 & 5086 \\
\hline Government College for Women University Sialkot & 44 & 13 & 19 & 7499 & 859 \\
\hline University of Okara & 40 & 14 & 20 & 5110 & 758 \\
\hline HITEC University & 39 & 32 & 89 & 14197 & 1119 \\
\hline Fatima Jinnah Women University & 38 & 16 & 37 & 6405 & 889 \\
\hline University of Wah & 35 & 66 & 431 & 36505 & 3832 \\
\hline Minhaj University & 30 & 14 & 23 & 2559 & 552 \\
\hline National College of Business Administration \& Economics & 29 & 15 & 19 & 2706 & 474 \\
\hline NFC Institute of Engineering \& Technology & 28 & 14 & 17 & 2318 & 359 \\
\hline King Edward Medical University & 28 & 12 & 13 & 3540 & 670 \\
\hline University of Health Sciences & 27 & 33 & 48 & 13823 & 1173 \\
\hline GIFT University & 27 & 18 & 25 & 3850 & 360 \\
\hline Ghazi University & 26 & 36 & 538 & 22951 & 3794 \\
\hline Kinnaird College for Women & 26 & 13 & 18 & 2763 & 545 \\
\hline Cholistan University of Veterinary and Animal Sciences Bahawalpur & 26 & 21 & 178 & 11073 & 2681 \\
\hline The University of Faisalabad & 25 & 12 & 12 & 2361 & 606 \\
\hline Namal Institute Mainwali & 24 & 17 & 32 & 6667 & 695 \\
\hline The Women University & 23 & 13 & 16 & 2012 & 238 \\
\hline University of South Asia & 21 & 73 & 625 & 31340 & 3125 \\
\hline University of Sialkot & 18 & 35 & 104 & 11703 & 943 \\
\hline
\end{tabular}




\begin{tabular}{|c|c|c|c|c|c|}
\hline University of Sahiwal & 16 & 16 & 19 & 2059 & 236 \\
\hline Institute of Southern Punjab & 15 & 28 & 81 & 6360 & 791 \\
\hline Government Sadiq College Women University & 12 & 10 & 10 & 1266 & 161 \\
\hline Lahore Leads University & 10 & 6 & 4 & 363 & 78 \\
\hline Beaconhouse National University & 9 & 29 & 50 & 6105 & 433 \\
\hline University of Narowal & 6 & 8 & 5 & 369 & 64 \\
\hline Imperial College of Business Studies & 5 & 16 & 19 & 1731 & 112 \\
\hline Muhammad Nawaz Sharif University of Engineering \& Technology & 5 & 24 & 61 & 2443 & 209 \\
\hline Rawalpindi Women University & 4 & 4 & 1 & 126 & 29 \\
\hline Pakistan Institute of Fashion \& Design & 3 & 3 & 1 & 75 & 15 \\
\hline University of Home Economics Lahore & 2 & 5 & 3 & 87 & 27 \\
\hline National College of Arts & 2 & 10 & 12 & 390 & 55 \\
\hline Institute for Art and Culture & 2 & 1 & 0 & 4 & 3 \\
\hline Institute of Management Sciences & 2 & 32 & 106 & 4106 & 294 \\
\hline Nur International University & 1 & 7 & 3 & 195 & 82 \\
\hline Fatima Jinnah Medical University Lahore & 1 & 2 & 0 & 9 & 12 \\
\hline Qarshi University & 1 & 1 & 0 & 4 & 1 \\
\hline University of Mainwali & 1 & 18 & 30 & 1077 & 70 \\
\hline Ali Institute of Education & 0 & 0 & 0 & 0 & 0 \\
\hline Hajvery University & 0 & 0 & 0 & 0 & 0 \\
\hline Institute of Management Sciences & 0 & 0 & 0 & 0 & 0 \\
\hline Lahore School of Economics & 0 & 0 & 0 & 0 & 0 \\
\hline Punjab Tianjin University of Technology Lahore & 0 & 0 & 0 & 0 & 0 \\
\hline Rawalpindi Medical University & 0 & 0 & 0 & 0 & 0 \\
\hline Virtual University of Pakistan & 0 & 0 & 0 & 0 & 0 \\
\hline Global Institute Lahore & 0 & 0 & 0 & 0 & 0 \\
\hline Faisalabad Medical University Faisalabad & 0 & 0 & 0 & 0 & 0 \\
\hline Times Institute Multan & 0 & 0 & 0 & 0 & 0 \\
\hline Grand Total & 5615 & 126 & 934 & 2754844 & 267677 \\
\hline
\end{tabular}

TABLE II. LIST OF ALL OF THE UNIVERSITIES OF SINDH PROVINCE

\begin{tabular}{|c|c|c|c|c|c|}
\hline University Name & $\begin{array}{l}\text { Total Number of } \\
\text { Scholars Visible }\end{array}$ & $\begin{array}{l}\text { Max of h- } \\
\text { index }\end{array}$ & $\begin{array}{l}\text { Max of } \\
\text { i10-index }\end{array}$ & $\begin{array}{l}\text { Sum of total } \\
\text { Citation }\end{array}$ & $\begin{array}{l}\text { Sum of Total } \\
\text { Paper Published }\end{array}$ \\
\hline Aga Khan University & 272 & 77 & 768 & 285556 & 22921 \\
\hline Mehran University of Engineering \& Technology & 255 & 27 & 54 & 46032 & 6319 \\
\hline University of Sindh & 244 & 57 & 224 & 66177 & 7736 \\
\hline University of Karachi & 227 & 76 & 769 & 208561 & 22388 \\
\hline Sukkur Institute of Business Administration & 166 & 26 & 67 & 23311 & 4763 \\
\hline NED University of Engineering \& Technology & 141 & 23 & 36 & 25188 & 2907 \\
\hline Institute of Business Management & 137 & 17 & 28 & 13298 & 2207 \\
\hline DOW University of Health Sciences & 113 & 44 & 224 & 44058 & 4687 \\
\hline Quaid-e-Awam University of Engineering Sciences \& Technology & 96 & 14 & 16 & 11771 & 1747 \\
\hline Institute of Business Administration & 73 & 11 & 11 & 5581 & 894 \\
\hline Iqra University & 68 & 29 & 70 & 10060 & 1212 \\
\hline Shah Abdul Latif University & 68 & 15 & 21 & 8694 & 1531 \\
\hline Sindh Agriculture University Tandojam & 66 & 16 & 29 & 15273 & 2657 \\
\hline Shaheed Zulfikar Ali Bhutto Institute of Science \& Technology & 64 & 16 & 23 & 5669 & 790 \\
\hline Hamdard University & 37 & 12 & 15 & 2601 & 692 \\
\hline
\end{tabular}




\begin{tabular}{|c|c|c|c|c|c|}
\hline Sir Syed University of Engineering \& Technology & 37 & 18 & 31 & 5020 & 821 \\
\hline Liaquat University of Medical \& Health Sciences & 37 & 15 & 30 & 7254 & 1470 \\
\hline Karachi Institute of Economics \& Technology & 36 & 12 & 13 & 4447 & 734 \\
\hline Sindh Madresatul Islam University & 34 & 16 & 22 & 3413 & 498 \\
\hline Zia-ud-Din University & 34 & 62 & 448 & 26485 & 3606 \\
\hline Dawood University of Engineering \& Technology & 27 & 21 & 29 & 5488 & 457 \\
\hline Jinnah Sindh Medical University & 25 & 34 & 65 & 8891 & 822 \\
\hline Isra University & 25 & 31 & 131 & 10317 & 1307 \\
\hline Indus University & 24 & 14 & 18 & 1230 & 227 \\
\hline Shaheed Benazir Bhutto University Shaheed Benazirabad & 24 & 7 & 6 & 919 & 279 \\
\hline Habib University & 22 & 15 & 21 & 3465 & 407 \\
\hline Mohammad Ali Jinnah University & 20 & 5 & 3 & 309 & 103 \\
\hline Barret Hodgson University & 19 & 8 & 8 & 1604 & 265 \\
\hline Jinnah University for Women & 16 & 10 & 12 & 1708 & 425 \\
\hline Benazir Bhutto Shaheed University Lyari & 15 & 25 & 69 & 2895 & 297 \\
\hline KASB Institute of Technology & 13 & 11 & 15 & 1053 & 158 \\
\hline Baqai Medical University & 10 & 28 & 51 & 6574 & 593 \\
\hline Preston University & 10 & 20 & 36 & 3107 & 317 \\
\hline Peoples University of Medical \& Health Sciences for Women & 9 & 10 & 14 & 869 & 212 \\
\hline Begum Nusrat Bhutto Women University Sukkur & 6 & 15 & 21 & 805 & 88 \\
\hline Shaheed Mohtarma Benazir Bhutto Medical University & 5 & 15 & 19 & 1343 & 73 \\
\hline Sindh Institute of Medical Sciences & 4 & 25 & 74 & 3743 & 496 \\
\hline Karachi School for Business \& Leadership & 4 & 17 & 24 & 1957 & 121 \\
\hline $\begin{array}{l}\text { Benazir Bhutto Shaheed University of Technology \& Skill } \\
\text { Development Khairpur Mirs }\end{array}$ & 4 & 7 & 6 & 330 & 14 \\
\hline Shaheed Benazir Bhutto University of Veterinary \& Animal Sciences & 3 & 11 & 13 & 1924 & 72 \\
\hline University of Sufism and Modern Sciences Bhitshah & 3 & 2 & 0 & 15 & 34 \\
\hline ILMA University & 2 & 3 & 1 & 45 & 32 \\
\hline Newport Institute of Communications \& Economics & 1 & 1 & 0 & 1 & 16 \\
\hline Nazeer Hussain University & 1 & 1 & 0 & 2 & 7 \\
\hline Shaheed Zulfiqar Ali Bhutto University of Law & 1 & 5 & 1 & 154 & 61 \\
\hline Government College University Hyderabad & 1 & 7 & 5 & 155 & 18 \\
\hline Textile Institute of Pakistan & 1 & 2 & 1 & 17 & 8 \\
\hline Dadabhoy Institute of Higher Education & 1 & 8 & 7 & 556 & 41 \\
\hline Emaan Institute of Management \& Sciences & 1 & 4 & 0 & 35 & 23 \\
\hline Gambat Institute of Medical Sciences & 0 & 0 & 0 & 0 & 0 \\
\hline Greenwich University & 0 & 0 & 0 & 0 & 0 \\
\hline Indus Valley School of Art \& Architecture & 0 & 0 & 0 & 0 & 0 \\
\hline Pakistan Naval Academy & 0 & 0 & 0 & 0 & 0 \\
\hline Preston Institute of Management Science \& Technology & 0 & 0 & 0 & 0 & 0 \\
\hline Shaheed Benazir Bhutto City University & 0 & 0 & 0 & 0 & 0 \\
\hline Shaheed Benazir Bhutto Dewan University & 0 & 0 & 0 & 0 & 0 \\
\hline Shaheed Benazir Bhutto University & 0 & 0 & 0 & 0 & 0 \\
\hline Sindh Institute of Management \& Technology & 0 & 0 & 0 & 0 & 0 \\
\hline Commecs Institute of Business \& Emerging Sciences & 0 & 0 & 0 & 0 & 0 \\
\hline The Shaikh Ayaz University Shikarpur & 0 & 0 & 0 & 0 & 0 \\
\hline Sohail University Karachi & 0 & 0 & 0 & 0 & 0 \\
\hline Grand Total & 2502 & 77 & 769 & 877960 & 97553 \\
\hline
\end{tabular}


TABLE III. LIST OF ALL OF THE UNIVERSitIES OF KHYBER PAKHTUNKHWA ProvinCE

\begin{tabular}{|c|c|c|c|c|c|}
\hline University Name & $\begin{array}{l}\text { Total Number of } \\
\text { Scholars Visible }\end{array}$ & $\begin{array}{l}\text { Max of h- } \\
\text { index }\end{array}$ & $\begin{array}{l}\text { Max of } \\
\text { i10-index }\end{array}$ & $\begin{array}{l}\text { Sum of total } \\
\text { Citation }\end{array}$ & $\begin{array}{l}\text { Sum of Total } \\
\text { Paper Published }\end{array}$ \\
\hline Abdul Wali Khan University & 203 & 65 & 224 & 125957 & 12436 \\
\hline University of Engineering \& Technology & 180 & 42 & 209 & 42800 & 4771 \\
\hline The University of Agriculture Peshawar & 167 & 69 & 668 & 242562 & 22600 \\
\hline University of Malakand & 101 & 28 & 71 & 48273 & 4766 \\
\hline Hazara University & 97 & 69 & 548 & 69170 & 7201 \\
\hline Ghulam Ishaq Khan Institute of Engineering Sciences \& Technology & 96 & 29 & 96 & 23788 & 2510 \\
\hline Kohat University of Science and Technology & 91 & 51 & 500 & 56387 & 6122 \\
\hline University of Haripur & 66 & 77 & 282 & 40119 & 2331 \\
\hline Gomal University & 59 & 66 & 535 & 72979 & 8813 \\
\hline University of Peshawar & 50 & 74 & 725 & 60776 & 5118 \\
\hline Islamia College University & 48 & 26 & 64 & 19194 & 1506 \\
\hline Sarhad University of Science \& Information Technology & 47 & 18 & 42 & 8955 & 1287 \\
\hline University of Swat & 46 & 26 & 39 & 12282 & 1015 \\
\hline University of Swabi & 46 & 47 & 153 & 20023 & 1721 \\
\hline Institute of Management Sciences & 42 & 61 & 545 & 29263 & 3921 \\
\hline Khyber Medical University & 41 & 15 & 23 & 10418 & 1245 \\
\hline Shaheed Benazir Bhutto University & 38 & 47 & 223 & 24598 & 2796 \\
\hline Abasyn University & 33 & 27 & 56 & 7647 & 949 \\
\hline Bacha Khan University & 31 & 53 & 484 & 23242 & 3508 \\
\hline CECOS University of Information Technology \& Emerging Sciences & 28 & 34 & 102 & 15183 & 966 \\
\hline Qurtaba University of Science \& Information Technology & 21 & 22 & 55 & 4089 & 255 \\
\hline University of Science \& Technology & 19 & 24 & 34 & 8164 & 450 \\
\hline Iqra National University & 15 & 13 & 19 & 1291 & 336 \\
\hline Khushal Khan Khattak University & 15 & 15 & 23 & 3066 & 552 \\
\hline University of Engineering \& Technology (UET) Mardan & 15 & 14 & 16 & 2170 & 546 \\
\hline Shaheed Benazir Bhutto Women University & 14 & 9 & 8 & 1234 & 266 \\
\hline Abbottabad University of Science and Technology (AUST) & 14 & 26 & 52 & 6448 & 561 \\
\hline $\begin{array}{l}\text { Pak-Austria Fachhochschule Institute of Applied Sciences and } \\
\text { Technology Haripur }\end{array}$ & 12 & 20 & 41 & 4452 & 345 \\
\hline Northern University & 10 & 65 & 564 & 26231 & 2947 \\
\hline Preston University & 10 & 20 & 36 & 3107 & 317 \\
\hline Women University Swabi & 8 & 18 & 28 & 2354 & 166 \\
\hline University of Chitral & 8 & 10 & 10 & 327 & 66 \\
\hline University of FATA & 7 & 12 & 12 & 1229 & 110 \\
\hline The University of Lakki Marwat & 5 & 10 & 11 & 585 & 96 \\
\hline Shuhada-e-Army Public School University of Technology Nowshera & 4 & 11 & 12 & 734 & 97 \\
\hline University of Buner & 2 & 12 & 15 & 1155 & 41 \\
\hline Women University Mardan & 1 & 2 & 0 & 14 & 3 \\
\hline City University of Science and Information Technology & 1 & 1 & 0 & 3 & 3 \\
\hline Brains Institute Peshawar & 1 & 1 & 0 & 4 & 3 \\
\hline Gandhara University & 1 & 4 & 0 & 26 & 14 \\
\hline Pakistan Military Academy & 0 & 0 & 0 & 0 & 0 \\
\hline Grand Total & 1693 & 77 & 725 & 1020299 & 102756 \\
\hline
\end{tabular}


TABLE IV. LIST OF ALL OF THE UNIVERSITIES OF BALUCHISTAN PROVINCE

\begin{tabular}{|c|c|c|c|c|c|}
\hline University Name & $\begin{array}{l}\text { Total Number of } \\
\text { Scholars Visible }\end{array}$ & $\begin{array}{l}\text { Max of h- } \\
\text { index }\end{array}$ & $\begin{array}{l}\text { Max of } \\
\text { i10-index }\end{array}$ & $\begin{array}{l}\text { Sum of total } \\
\text { Citation }\end{array}$ & $\begin{array}{l}\text { Sum of Total } \\
\text { Paper Published }\end{array}$ \\
\hline $\begin{array}{l}\text { Balochistan University of Information Technology Engineering \& } \\
\text { Management Sciences (BUITEMS) }\end{array}$ & 115 & 21 & 41 & 18383 & 2185 \\
\hline University of Balochistan & 40 & 35 & 120 & 12518 & 1910 \\
\hline Lasbela University of Agriculture Water \& Marine Sciences & 19 & 21 & 40 & 3561 & 611 \\
\hline Balochistan University of Engineering \& Technology & 11 & 8 & 8 & 603 & 135 \\
\hline University of Turbat & 7 & 11 & 14 & 1386 & 120 \\
\hline University of Loralai & 6 & 6 & 4 & 740 & 78 \\
\hline Sardar Bahadur Khan Women University & 3 & 4 & 1 & 100 & 33 \\
\hline Al-Hamd Islamic University & 0 & 0 & 0 & 0 & 0 \\
\hline Mir Chakar Khan Rind University Sibi & 0 & 0 & 0 & 0 & 0 \\
\hline The Bolan University of Medical \& Health Sciences & 0 & 0 & 0 & 0 & 0 \\
\hline Grand Total & 201 & 35 & 120 & 37291 & 5072 \\
\hline
\end{tabular}

Islamabad is the capital of Pakistan and most of the topranked universities of Pakistan are located in the Capital Territory. By and large the public visibility of researchers on Google Scholar is higher whenever contrasted with different areas of Pakistan and all 23 universities have visibility on Google Scholar. Table V shows the quick summary of all Universities in Islamabad.

Azad Jammu \& Kashmir is an autonomous region of Pakistan. Mirpur University of Science \& Technology and the University of Azad Jammu \& Kashmir are two major Universities in this region. Two universities of Azad Jammu \&
Kashmir area are not visible on GS. Table VI features significant Google Scholar pointers of this state.

Gilgit Baltistan is a remote area of Pakistan with a limited population. Just two Universities are situated in this locale. Table VII shows the number of academicians publically visible on Google Scholar.

One of the main purposes of this study to identify the best researchers in Pakistan. Table VIII shows the list of top ten Pakistani Researchers based on their total number of citations.

The h-index is one of the main indicators to reflect the quality of research papers. Table IX displays a list of the top ten Pakistani researchers based on the Google Scholar h-index.

TABLE V. LIST OF ALL OF THE UNIVERSITIES OF ISLAMABAD CAPITAL TERRITORY

\begin{tabular}{|c|c|c|c|c|c|}
\hline University Name & $\begin{array}{l}\text { Total Number of } \\
\text { Scholars Visible }\end{array}$ & $\begin{array}{l}\text { Max of h- } \\
\text { index }\end{array}$ & $\begin{array}{l}\text { Max of } \\
\text { i10-index }\end{array}$ & $\begin{array}{l}\text { Sum of total } \\
\text { Citation }\end{array}$ & $\begin{array}{l}\text { Sum of Total } \\
\text { Paper Published }\end{array}$ \\
\hline National University of Sciences \& Technology & 764 & 54 & 239 & 202514 & 20809 \\
\hline Quaid-i-Azam University & 439 & 79 & 695 & 423528 & 36318 \\
\hline COMSATS Institute of Information Technology & 421 & 69 & 688 & 282658 & 19610 \\
\hline International Islamic University & 324 & 81 & 822 & 207479 & 17095 \\
\hline National University of Computer \& Emerging Sciences & 286 & 45 & 198 & 57590 & 6449 \\
\hline Bahria University & 200 & 29 & 94 & 30839 & 4658 \\
\hline Pakistan Institute of Engineering \& Applied Sciences & 157 & 75 & 815 & 110381 & 10823 \\
\hline Riphah International University & 150 & 74 & 613 & 65224 & 7783 \\
\hline Air University & 134 & 91 & 711 & 77741 & 5177 \\
\hline Shifa Tameer-e-Millat University & 129 & 26 & 99 & 17318 & 2276 \\
\hline Foundation University Islamabad & 97 & 36 & 69 & 19577 & 1735 \\
\hline National University of Modern Languages & 76 & 17 & 34 & 6350 & 1082 \\
\hline Institute of Space Technology & 65 & 34 & 66 & 25886 & 2026 \\
\hline Capital University of Science \& Technology & 49 & 22 & 60 & 15760 & 1468 \\
\hline Allama Iqbal Open University & 45 & 24 & 47 & 11672 & 1172 \\
\hline National University of Technology (NUTECH) Islamabad & 31 & 37 & 134 & 10563 & 937 \\
\hline Pakistan Institute of Development Economics (PIDE) & 22 & 23 & 46 & 12498 & 729 \\
\hline
\end{tabular}




\begin{tabular}{|c|c|c|c|c|c|}
\hline Health Services Academy HSA Islamabad & 14 & 53 & 74 & 43911 & 710 \\
\hline National Defense University & 12 & 15 & 21 & 1572 & 358 \\
\hline Shaheed Zulfiqar Ali Bhutto Medical University & 9 & 22 & 43 & 3778 & 892 \\
\hline Federal Urdu University of Arts Sciences \& Technology & 8 & 11 & 15 & 1328 & 191 \\
\hline Sir Syed (CASE) Institute of Technology & 4 & 10 & 11 & 893 & 127 \\
\hline Muslim Youth University & 4 & 2 & 0 & 11 & 7 \\
\hline Grand Total & 3440 & 91 & 822 & 1629071 & 142432 \\
\hline
\end{tabular}

TABLE VI. LIST OF ALL OF THE UNIVERSITIES OF AZAD JAMMU AND KASHMIR REGION

\begin{tabular}{|c|c|c|c|c|c|}
\hline University Name & $\begin{array}{l}\text { Total Number of } \\
\text { Scholars Visible }\end{array}$ & $\begin{array}{l}\text { Max of h- } \\
\text { index }\end{array}$ & $\begin{array}{l}\text { Max of } \\
\text { i10-index }\end{array}$ & $\begin{array}{l}\text { Sum of total } \\
\text { Citation }\end{array}$ & $\begin{array}{l}\text { Sum of Total } \\
\text { Paper Published }\end{array}$ \\
\hline Mirpur University of Science \& Technology & 91 & 34 & 151 & 25648 & 2570 \\
\hline University of Azad Jammu \& Kashmir & 71 & 75 & 669 & 98498 & 5329 \\
\hline University of Poonch & 47 & 23 & 40 & 13217 & 3245 \\
\hline University of Kotli Azad Jammu and Kashmir & 21 & 8 & 6 & 1357 & 202 \\
\hline Women University of Azad Jammu \& Kashmir & 9 & 10 & 11 & 1390 & 257 \\
\hline AlKhair University & 0 & 0 & 0 & 0 & 0 \\
\hline Mohi-ud-Din Islamic University & 0 & 0 & 0 & 0 & 0 \\
\hline Grand Total & 239 & 75 & 669 & 140110 & 11603 \\
\hline
\end{tabular}

TABLE VII. LIST OF ALL OF THE UNIVERSITIES OF GILGIT BALTISTAN

\begin{tabular}{|c|c|c|c|c|c|}
\hline University Name & $\begin{array}{l}\text { Total Number of } \\
\text { Scholars Visible }\end{array}$ & $\begin{array}{l}\text { Max of h- } \\
\text { index }\end{array}$ & $\begin{array}{l}\text { Max of } \\
\text { i10-index }\end{array}$ & $\begin{array}{l}\text { Sum of total } \\
\text { Citation }\end{array}$ & $\begin{array}{l}\text { Sum of Total } \\
\text { Paper Published }\end{array}$ \\
\hline Karakurum International University & 68 & 78 & 770 & 58333 & 6253 \\
\hline University of Baltistan Skardu & 11 & 13 & 13 & 2645 & 197 \\
\hline Grand Total & 79 & 78 & 770 & 60978 & 6450 \\
\hline
\end{tabular}

TABLE VIII. LIST OF TOP TEN PAKISTANI RESEARCHERS BASED ON TOTAL CITATIONS

\begin{tabular}{|c|c|c|c|c|c|c|c|}
\hline Google Scholar ID & Scholar Name & Affiliation & $\begin{array}{l}\text { Total } \\
\text { Citations }\end{array}$ & h-index & $\begin{array}{l}\text { i10- } \\
\text { index }\end{array}$ & $\begin{array}{l}\text { Citations in } \\
\text { last } 5 \text { Years }\end{array}$ & $\begin{array}{l}\text { Total Paper } \\
\text { Published }\end{array}$ \\
\hline vUSWHc8AAAAJ & Dr. Muhammad Naeem Ahmed & $\begin{array}{l}\text { University of Azad Jammu \& } \\
\text { Kashmir }\end{array}$ & 77300 & 75 & 669 & 27181 & 2904 \\
\hline _3WBQxYAAAAJ & Muhammad Arshad Sajjad & Air University & 53397 & 91 & 711 & 41529 & 2002 \\
\hline B6TB8IEAAAAJ & Prof. Dr. Hidayatur Rahman & $\begin{array}{l}\text { The University of Agriculture } \\
\text { Peshawar }\end{array}$ & 47277 & 69 & 668 & 28537 & 2978 \\
\hline ByAexSYAAAAJ & Muhammad Akbar Zafar Khan & Islamia University & 41810 & 60 & 546 & 31374 & 2799 \\
\hline nAFs720AAAAJ & Aysha Habib Khan & Aga Khan University & 41479 & 77 & 768 & 20955 & 2980 \\
\hline E82kqSgAAAAJ & Ejaz Khan & $\begin{array}{l}\text { Health Services Academy } \\
\text { HSA Islamabad }\end{array}$ & 41218 & 53 & 74 & 40108 & 130 \\
\hline upXMs64AAAAJ & $\begin{array}{l}\text { Prof. Dr. Muhammad Tahir } \\
\text { Hussain }\end{array}$ & National Textile University & 39567 & 85 & 934 & 20767 & 2979 \\
\hline Vqh3MKMAAAAJ & Dr. Farooq Ahmad & $\begin{array}{l}\text { University of Engineering \& } \\
\text { Technology Lahore }\end{array}$ & 38209 & 81 & 780 & 23245 & 2957 \\
\hline Hy-zuEwAAAAJ & SAIF UR REHMAN & $\begin{array}{l}\text { University of Management \& } \\
\text { Technology }\end{array}$ & 37991 & 76 & 691 & 19400 & 2976 \\
\hline -wnLx6gAAAAJ & Dr. Tania Ahmed Shakoori & University of Lahore & 37938 & 92 & 354 & 18399 & 947 \\
\hline
\end{tabular}


TABLE IX. LIST OF TOP TEN PAKISTANI RESEARCHERS BASED ON H-INDEX

\begin{tabular}{|c|c|c|c|c|c|c|}
\hline Google Scholar ID & Scholar Name & Affiliation & h-Index & $\begin{array}{l}\text { Total } \\
\text { Citations }\end{array}$ & $\begin{array}{l}\text { i10- } \\
\text { index }\end{array}$ & $\begin{array}{l}\text { Total Paper } \\
\text { Published }\end{array}$ \\
\hline 918oSH0AAAAJ & Kauser Abdulla Malik & Forman Christian College & 126 & 37925 & 298 & 622 \\
\hline QjPoerMAAAAJ & MA Saeed & University of Education & 109 & 37220 & 416 & 1030 \\
\hline -wnLx6gAAAAJ & Dr. Tania Ahmed Shakoori & University of Lahore & 92 & 37938 & 354 & 947 \\
\hline _3WBQXYAAAAJ & Muhammad Arshad Sajjad & Air University & 91 & 53397 & 711 & 2002 \\
\hline upXMs64AAAAJ & Prof. Dr. Muhammad Tahir Hussain & National Textile University & 85 & 39567 & 934 & 2979 \\
\hline Vqh3MKMAAAAJ & Dr. Farooq Ahmad & $\begin{array}{l}\text { University of Engineering \& } \\
\text { Technology Lahore }\end{array}$ & 81 & 38209 & 780 & 2957 \\
\hline KqaU3UMAAAAJ & Asma Hussain & International Islamic University & 81 & 34537 & 822 & 2977 \\
\hline b_VQd2EAAAAJ & Amjad Khan & Quaid-i-Azam University & 79 & 33803 & 586 & 2889 \\
\hline TqhlyQMAAAAJ & Asif Khan & $\begin{array}{l}\text { Karakurum International } \\
\text { University }\end{array}$ & 78 & 36430 & 770 & 2985 \\
\hline nAFs720AAAAJ & Aysha Habib Khan & Aga Khan University & 77 & 41479 & 768 & 2980 \\
\hline
\end{tabular}

\section{ETHICAL CONSIDERATIONS}

Ethical consideration is one of the most important parts of any kind of research. According to Bryman and Bell [23], it is mandatory for the author of a research paper to acknowledge the works of other researchers by use of the referencing system recommended by the publication committee of the journal, where the paper is supposed to be published. It is highly unethical if a scholar claimed the authorship of a paper, which is not written by him/her. In the previous section, Tables VIII and IX highlighted the top researchers of Pakistan based on total number of citations and highest h-index rankings respectively, which are currently updated on GS. The authors of this paper believe that many of the scholar's names shown in these tables did not verify their paper lists on GS, which is causing misrepresentation of profiles. Furthermore, such actions restraining other legitimate researchers to become visible on top of the list. There might be many reasons why scholars on GS are not validating their paper on GS. Two common reasons are mentioned in the remainder of this section.

1) GS automatically generate the list of citations and paper published by a scholar based on its ranking algorithms. Scholars are either to set manual update and verify each entry before being added to his/her profile, or scholars are supposed to deleted papers that are not written by them and mistakenly added to their profile due to similarity of name or co-author affiliations. However, due to time constraints and busy schedules, scholars are not visiting GS to verify their profiles regularly.

2) Scholars might deliberately add a few high-quality papers with higher citations in their profiles to improve their visibility on GS. According to the GS ranking algorithm [24], profiles with higher citations appear first in the university's GS list, as well as, on the Google search engine. It is a high probability that papers that appear in the top position might get more citations compared to new papers that get less attention from the visitors of GS as these papers hide at the bottom of the list. Other possible motives for adding non-legitimate papers are to impress peers or to gain research funding as most of the sponsors are looking for GS research indicators to select the best researchers for their projects.

\section{DISCUSSION AND FUTURE WORK}

The Google scholar is a very popular and useful tool to showcase the author's profile over the internet. Many universities are using Google Suite for email and other administrative tasks, therefore, it is easier for them to integrate university faculty research profiles with GS. In this study, the authors collected the GS scholar data (total 13769 Scholars) of all 217 Pakistani recognized universities. Twenty-eight universities have no representation on Google Scholar at all. Results showed that universities from Islamabad Capital Territory have high visibility compared to other autonomous areas of Pakistan. In general, the number of scholars' visibility on GS is logical and it is representing the population of the four provinces of Pakistan, where, Punjab is leading followed by Sindh, Khyber Pakhtunkhwa, and Baluchistan. However, individual academic indicators of many top researchers of Pakistan from their public profiles are misrepresenting and they contained papers and citations, which may not belong to specific scholars.

Misrepresentation of information on public profiles is a serious ethical issue. This misrepresentation of data might be the result of the auto-generation of citation by GS or any other social stress on the scholar by the academic environment. It is the responsibility of the scholars to make sure that they frequently check their GS profiles and remove papers that were added by GS automatically in authors' profiles, which were not written by them. As a responsible citizen of the research community, scholars should only take ownership of those papers on public profiles that were produced by them and not those whose authors' names are similar to them. Furthermore, there is a need for strict control on GS, which makes sure only legitimate papers are added on GS public profiles, both by scholars and auto-recommendation features of GS. The GS may add the feature of verifying from one of the co-authors the legitimation ownership of the scholar.

Research plays a vital role in the ranking of universities. Universities evaluating bodies that issue university rankings, such as, Higher Education Commission of Pakistan, QS, and Time university rankings required universities to provide them 
their research outcomes on a yearly basis. GS is a very useful tool for universities to publicly present their research achievement systematically. As a regulatory body, HEC has a good influence over Pakistan universities. Therefore, it is easier for HEC to advise universities to maintain their research activities on GS. Universities can make sure that all scholars affiliated with their university have legitimate public profiles visible on GS and scholars update their profiles regularly to avoid ethical and social issues, which were discussed in the previous section. Universities/DAI make sure that scholars will not get any benefit because of his/her incorrect GS profile.

Limitations of this study are already discussed in a dedicated section. The authors are planning to add two more features in MAKGBOT to overcome these limitations. Firstly, MAKGBOT should support real-time or periodic updates. As soon as, the new university is added to the HEC repository or the paper is published in the public profile of a Pakistani scholar, the system will update the results and provide basic reports. Secondly, MAKGBOT should check the legitimacy of the papers by verifying the scholar's name in the published paper, which is added to the public profile of GS.

\section{REFERENCES}

[1] U. Sandstrom and P. v. d. Besselaar, "Quantity and/or Quality? The Importance of Publishing Many Papers,” PLoS ONE, vol. 11, no. 11, pp. 1-16, 2016.

[2] C. Bosquet and P.-P. Combes, "Are academics who publish more also more cited? Individual determinants of publication and citation records," Scientometrics,Springer,Akadémiai Kiadó, vol. 97, no. 3, pp. 831-857, 2013.

[3] L. Butler, "Explaining Australia's increased share of ISI publicationsthe effects of a funding formula based on publication counts," Research Policy, vol. 32, no. 1, pp. 143-155, 2003.

[4] H. Dijstelbloem, F. Huisman, F. Miedema and W. Mijnhardt, "Science in Transition status report: Debate, progress and recommendations," Science in Transition, Amsterdam, 2014.

[5] M. Tober, "PubMed, ScienceDirect, Scopus or Google Scholar - Which is the best search engine for an effective literature research in laser medicine?," Medical Laser Application, vol. 26, no. 3, pp. 139-144, 2011.

[6] J. L. Ortega, "6 - Google Scholar: on the shoulders of a giant," in Academic Search Engines, Chandos Publishing, 2014, pp. 109-141.

[7] E. Orduna-Malea, J. M. Ayllón, A. Martín-Martín and E. D. López-Cózar , "Methods for estimating the size of Google Scholar," Scientometrics, vol. 104, no. 3, pp. 931-949, 2015.

[8] R. Housewright, R. C. Schonfeld and K. Wulfson, "Ithaka S+R|JISC|RLUK UK Survey of Academics 2012," 2013.
[9] B. Kramer and J. Bosman, "Innovations in scholarly communication global survey on research tool usage," F1000Research, vol. 5, no. 692, pp. 1-13, 2016.

[10] E. D. López-Cózar, E. Orduna-Malea, A. Martín-Martín and J. . M. Ayllón, "Google Scholar: The Big Data Bibliographic Tool," in Research Analytics: Boosting University Productivity and Competitiveness through Scientometrics, F. J. Cantú-Ortiz, Ed., CRC Press, 2017, pp. 59-80.

[11] A.-W. K. Harzing and R. v. d. Wal, "Google Scholar as a new source for citation analysis?," Ethics in Science and Environmental Politics, vol. 8, no. 1, pp. 61-73, 2008.

[12] S. Pylarinou and S. Kapidakis, "Tracking Scholarly Publishing of Hospitals Using MEDLINE, Scopus, WoS and Google Scholar,” Journal of Hospital Librarianship, vol. 17, no. 3, pp. 209-216, 2017.

[13] A. Y. Gasparyan, B. Nurmashev, M. Yessirkepov, D. A. Endovitskiy, A. A. Voronov and G. D. Kitas, "Researcher and Author Profiles: Opportunities, Advantages, and Limitations," Journal of Korean medical science, vol. 32, no. 11, pp. 1749-1756, 2017.

[14] J. Gao and T. Zhou, "Retractions: stamp out fake peer review," Nature, vol. 546, p. 33, 2017.

[15] A. G. Smith, "Benchmarking Google Scholar with the New Zealand PBRF research assessment exercise," Scientometrics, vol. 74, no. 2, pp. 309-316, 2007.

[16] "HEC Recognised Universities and Degree Awarding Institutions," HEC, [Online]. Available: https://hec.gov.pk/english/Universities/pages/ recognised.aspx. [Accessed 10 Jan 2021].

[17] “pypi.org," [Online]. Available: https://pypi.org/project/beautifulsoup4/. [Accessed 8 November 2020].

[18] "pypi.org," [Online]. Available: https://pypi.org/project/scholarly/. [Accessed 8 November 2020].

[19] "Universities Ranking," HEC, [Online]. Available: https://www.hec.gov.pk/english/universities/Pages/AJK/rank.aspx. [Accessed 26 Dec 2020].

[20] "QS World University Ranking," QS, [Online]. Available: https://www.topuniversities.com/university-rankings/world-universityrankings/2020. [Accessed 28 December 2020].

[21] “THE World University Rankings," THE, [Online]. Available: https://www.timeshighereducation.com/world-universityrankings/2020/worldranking\#!/page/0/length/25/locations/PK/sort_by/rank/sort_order/asc/cols /stats. [Accessed 28 December 2020].

[22] "University of Punjab," [Online]. Available: http://pu.edu.pk/page/show/ historyandpride.html . [Accessed 28 December 2020].

[23] E. Bell, A. Bryman and B. Harley, Business Research Methods, 5th Edition ed., Oxford University Press, 2018.

[24] J. Beel and B. Gipp, "Google Scholar's Ranking Algorithm: An Introductory Overview," in Proceedings of the 12th International Conference on Scientometrics and Informetrics (ISSI'09), Rio de Janeiro (Brazil), 2009. 